\title{
Downy mildew of lavender caused by Peronospora belbahrii in Israel
}

\author{
Marco Thines $^{1,2}$ (D) Anthony Buaya ${ }^{1} \cdot$ Sebastian Ploch ${ }^{1} \cdot$ Yariv Ben Naim $^{3} \cdot$ Yigal Cohen $^{3}$
}

Received: 6 July 2020 / Revised: 20 October 2020 / Accepted: 22 October 2020

(C) The Author(s) 2020

\begin{abstract}
Peronospora belbahrii is one of the most destructive downy mildew diseases that has emerged throughout the past two decades. Due to the lack of quarantine regulations and its possible seed-borne nature, it has spread globally and is now present in most areas in which basil is produced. While most obligate biotrophic, plant parasitic oomycetes are highly host-specific, there are a few that have a wider host range, e.g. Albugo candida, Bremia tulasnei, and Pseudoperonospora cubensis. Recently, it was shown that Peronospora belbahrii is able to infect Rosmarinus, Nepetia, and Micromeria in Israel in cross-infection trials, hinting an extended host range for also this pathogen. In this study, a newly occurring downy mildew pathogen on lavender was investigated with respect to its morphology and phylogeny, and it is shown that it belongs to Peronospora belbahrii as well. Thus, it seems that Peronospora belbahrii is currently extending its host range to additional members of the tribe Mentheae and Ocimeae. Therefore, it seems advisable to scrutinise all commonly used members of these tribes in order to avoid further spread of virulent genotypes.
\end{abstract}

Keywords Downy mildew $\cdot$ Evolution $\cdot$ Host jump $\cdot$ New host $\cdot$ Peronosporaceae

\section{Introduction}

Currently, there are more than 700 species of oomycetes known to cause downy mildew disease on a great variety of Angiosperm hosts (Constantinescu 1991; Thines and Choi 2016). Even though not members of the kingdom Mycota, but of the largely unrelated Straminipila (Beakes and Thines 2017), the downy mildew pathogens have evolved into filamentous, osmotrophic, and obligate biotrophic pathogens in parallel to their fungal counterparts. Several downy mildew pathogens, such as Plasmopara destructor (Görg et al. 2017), Pl. halstedii (Sharma et al. 2015; Trojanová et al. 2017),

Section Editor: Meike Piepenbring

Marco Thines

m.thines@thines-lab.eu

1 Senckenberg Biodiversity and Climate Research Centre, Senckenberganlage 25, 60325 Frankfurt am Main, Germany

2 Department of Biological Sciences, Institute of Ecology, Evolution, and Diversity, Goethe University, Max-von-Laue-Str. 13, 60486 Frankfurt am Main, Germany

3 Faculty of Life Sciences, Bar Ilan University, 529000 Ramat Gan, Israel
Peronospora belbahrii (Thines et al. 2009, 2020b), Pe. effusa (Choi et al. 2015a, Klein et al. 2020), and Pe. tabacina (Derevnina et al. 2015), cause economically important downy mildew diseases, e.g. of balsamines, sunflowers, basil, spinach, and tobacco, respectively.

Most downy mildew species have only very limited host ranges (Gäumann 1923, Gustavsson 1959), as evidenced by both cross-infection trials (e.g. Gäumann 1923) and molecular phylogenetic investigations (e.g. Voglmayr 2003; Göker et al. 2004; García-Blázquez et al. 2008). However, there are a few downy mildew species that have broader host ranges, e.g. Pseudoperonospora cubensis (Runge and Thines 2009, 2012; Runge et al. 2012, Cohen et al. 2015), Bremia tulasnei (Choi and Thines 2015), Pe. somniferi (Voglmayr et al. 2014), and Pe. belbahrii (Ben Naim et al. 2019). While in the first two cases it can be assumed that the broad host range is due to different stages of radiation after a host jump event (Thines 2019), the latter two cases are more likely a reflection of an alien pathogen extending its host range to related plants, previously naïve to downy mildew infestation (Thines 2019). The latter case can pose a substantial threat to plant production, if there are related commercially produced hosts that can be infected by the invasive pathogen.

Within just 5 years after its emergence in basil production in Europe, $P$ e. belbahrii became a major pathogen throughout 
the world, likely due to the trade with infested seed lots and the delayed recognition of it as a new, previously unrecognised species (Belbahri et al. 2005; Falach-Block et al. 2019; Thines et al. 2009). Apart from basil, other species have been reported as potential hosts for Pe. belbahrii, such as coleus, sage, nepeta, and rosemary (Ben Naim et al. 2019; Thines et al. 2009). While the pathogen of coleus was recently described as a species of its own (Hoffmeister et al. 2020), rosemary, nepeta, and some sage species where identified as potential hosts of Pe. belbahrii by cross-inoculation experiments (Ben Naim et al. 2019). However, cross-infection trials usually involve pathogen loads that are much higher than expected under natural conditions and thus are not conclusive with respect to realised host ranges under field conditions. This is exemplified by Bryonia dioica, which is a common perennial member of the Cucurbitaceae in Central Europe. While the species can be readily infected with $P$ s. cubensis under laboratory conditions (Runge and Thines 2009, Runge et al. 2012), it has, to our knowledge, not been reported as a host under natural conditions.

During a scrutiny of culinary herbs in nurseries in Israel, lavender plants (Lavandula angustifolia) exhibiting symptoms of downy mildew disease were observed. So far, lavender has not been reported as a host to any downy mildew species. Lavender belongs to the same tribe as basil (Ocimeae) and the same subfamily (Nepetoideae) as other species that could be infected with Pe. belbahrii in a laboratory setting. Thus, it was the aim of the current study to investigate, if the observed infection was caused by this species, which would call for a close monitoring of basil downy mildew in areas in which lavender is grown, in order to minimise the risk of a host jump to this important perennial herb and ornamental.

\section{Material and methods}

\section{Plant material and microscopic investigation}

Lavender plants showing symptoms of downy mildew disease were collected in summer 2019 from a nursery at Nehalim, Israel. Specimens were air-dried between paper towels and stored in closed envelopes for 2 months to ensure that no live structures could accidentally be released to the environment. Small parts of the specimens were then collected in 2-ml tubes for DNA extraction or alternatively distributed onto microscopic slides in drops of $70 \%$ aqueous lactic acid solution and covered with coverslips. Afterwards, observations of the morphological characteristics as seen in DIC were done at $x$ 400 magnification using a Zeiss Imager 2 microscope with an Axiocam colour camera (Zeiss, Oberkochen, Germany). Measurements were done in Axiovision (Zeiss, Oberkochen, Germany) on the pictures taken. Measurements are reported as (minimum-)mean minus standard deviation-mean-mean plus standard deviation(-maximum). A dried specimen was deposited in the Herbarium Senckenbergianum (FR) under the accession number FR-0246023.

\section{Infectivity tests}

Conidia were collected from downy mildew-infected lavender plants into cold distilled water; their number was adjusted to $5000 \mathrm{spores} / \mathrm{ml}$, and were spray-inoculated onto the upper leaf surfaces of basil plants (cv. Peri at 2-4 leaf stage) using a fine glass atomiser. Inoculated plants were incubated in a dew chamber at $18^{\circ} \mathrm{C}$ in the dark for the first $15 \mathrm{~h}$ after inoculation to ensure infection and, thereafter, for 6 days at $25^{\circ} \mathrm{C}$ under continuous illumination $\left(120 \mu\right.$ mole $\left.\mathrm{m}^{2} \mathrm{~s}^{-1}\right)$ to allow for symptom production. Plants were returned to the dew chamber on the seventh day post inoculation to enable sporulation of the pathogen on leaves of the inoculated plants. Uninoculated plants served as control.

\section{DNA preparation, $P C R$, and sequencing}

DNA was extracted from small leaf parts containing conidiophores and hyphae as described earlier (Mishra et al. 2018). PCR amplifications of the barcode loci ITS and cox 2 were done as outlined by Choi et al. (2015b). The PCR products were sequenced bidirectionally using the primers employed in PCR at the laboratory centre of the Senckenberg Biodiversity and Climate Research Centre (SBiK-F). Sequences of the ITS and the cox 2 barcode were deposited in GenBank (https:// www.ncbi.nlm.nih.gov/Genbank/) under the accession numbers MT588812 and MT602519, respectively.

\section{Alignment and phylogenetic analysis}

Sequences similar to those obtained in the present study were downloaded from GenBank (https://www.ncbi.nlm.nih.gov/ Genbank/) by searching the nucleotide database using blastn (Altschul et al. 1990) and selecting representative reference sequences. Aligned sequences were downloaded and from the results, and subsequently, over-represented sequence types were removed to keep only two (in unclear cases up to five) sequences per sequence type. Subsequently, alignments were done using the TrEase webserver (https://thines-lab. senckenberg.de/trease) with muscle (Edgar 2004) applying standard settings. Leading and trailing gaps were removed, and afterwards, alignments were uploaded to the TrEase webserver (https://thines-lab.senckenberg.de/trease) for phylogenetic inference. Minimum evolution inference was done using FastTree (Price et al. 2010) with the GTR substitution model and 1000 bootstrap replicates. Maximum likelihood inference was done using RAxML v8 (Stamatakis 2014) with the GTRGAMMA substitution model. Bayesian 
Inference with six gamma categories was calculated with MrBayes v3.2 (Ronquist et al. 2012) running for 5 million generations, with sampling every 10,000 th tree, and to ensure sampling from the stationary phase, the first $30 \%$ of the trees were discarded before calculating posterior probabilities.

\section{Results}

\section{Infectivity tests}

Typical downy mildew lesions with profuse sporulation were observed in the inoculated basil plants at 7 days postinoculation (dpi), supporting that the lavender downy mildew pathogen can cause downy mildew in sweet basil.

\section{Morphology}

Leaf areas of lavender plants infected with downy mildew were slightly discoloured as seen from above (Fig. 1a). Lesions were not clearly vein-delimited and gradually transitioning into the healthy leaf colour at their outer limits. On the lower leaf surface, a sparse to slightly crowded outgrowth of hyaline conidiophores from the stomata was observed. Conidia were very dark purplish-brown, rendering the lesions easily visible when turning the leaves. Conidiophores were erect and monopodially branched to sometimes sub-dichotomously branched with up to 7 (rarely 8) orders, and were (369-)451-606-761(-936) $\mu \mathrm{m}$ long, (11-)11.2-12.3-13.4(-15) $\mu \mathrm{m}$ wide, sometimes slightly swollen at the base; trunk (240-)280-375-470(-595) $\mu \mathrm{m}$, ratio total length to trunk length (1.5-)1.5-1.6-1.7(-1.8), $n=10$. Ultimate branchlets were usually curved, with an obtuse to slightly pointed tip, mostly paired (70\%) and differed in length, with the longer ones measuring (8-)12.9-17.3-21.7(-30) $\mu \mathrm{m}$, the shorter ones measured (4-)6.4-9-11.6(-17) $\mu \mathrm{m}$, and the ratio of the longer to the shorter ultimate branchlet was (1.08-)1.53-1.98-2.43(-3.95) $\mu \mathrm{m}, n=100$; the branching of the ultimate ramification was mostly rectangular. Conidia were broadly ellipsoidal, (21.5-)25.7-28-30.3(-33) $\mu \mathrm{m}$ long, (17-)21-22.9-24.8(-27.5) wide, with a length to breadth ratio of (1.06-)1.14-1.23-1.32(-1.52), $n=100$, directly germinating with a germ tube. Thus, the main characteristics (ratio of the longer to the shorter ultimate branchlets and conidial dimensions) agree very well with the measurements reported in Thines et al. (2009), leaving no doubt that the species affecting lavender in Israel is Peronospora belbahrii. An overview of the morphology is given in Fig. 1.

\section{Phylogeny}

Both in the cox2-based (Fig. 2a) and in the ITS-based (Fig. 2b) phylogenetic reconstruction, the downy mildew pathogen from lavender in Israel grouped together with samples of $P e$. belbahrii from Ocimum basilicum from several countries in all phylogenetic analyses and mostly with strong support. Within $P$ e. belbahrii the phylogenetic resolution was low with some sequence variation, but no clear-cut geographical pattern was seen. The recently described species $P e$. choii was inferred as the sister group to $P e$. belbahrii in all analyses, with moderate support. These two species were embedded in a clade containing several other species on culinary and ornamental herbs, including the economically important sage pathogen $P e$. salviae-officinalis. The whole group, all of which are pathogens of the subfamily Nepetoideae of the family Lamiaceae, was supported with strong to maximum support in all analyses on both loci. Apart from this group, two species groups with a limited host range, one including pathogens from Caryophyllales (including the economically important species $P e$. variabilis) and the other containing pathogens from Ranunculaceae (including the widespread species $P e$. ficariae), were resolved as monophyletic with moderate support in the cox2-based phylogenetic reconstruction (Fig. 2a). In the ITS-based phylogenetic reconstructions, no additional groupings apart from the Nepetoideae-infecting species received significant support. Based on both cox 2 and ITS sequences, the downy mildew pathogen from lavender in Israel could unambiguously be assigned to Pe. belbahrii.

\section{Discussion}

Many oomycete species are restricted in their host ranges and by this originally tied to the natural distribution of their hosts. This originally applied not only to wild plants but also to cultivated ones. However, with the increasing mobility of people and the global spread of popular crops, new cultivated and domesticated species were widely distributed, such as potato (Solanum tuberosum) and tomato (So. lycopersicum). The resulting global trade resulted in the risk to distribute pathogens from the natural range of the host as well, and consequently, pathogens soon followed their hosts, such as Phytophthora infestans, causing potato late blight (de Bary 1876; Yoshida et al. 2013); Plasmopara viticola, causing grape downy mildew (Viennot-Bourgin 1949, Fontaine et al. 2013; Yin et al. 2017; Brilli et al. 2018); Pl. halstedii, causing downy mildew of sunflower (Novotel'nova 1962, 1966; Trojanová et al. 2017); and, more recently, Peronospora aquilegiicola, causing Aquilegia downy mildew (Thines et al. 2019, 2020a). Some of these introductions had devastating effects: Ph. infestans, which triggered the Great Potato Famine, caused the death of hundreds of thousands of people in Ireland and continental Europe (Gráda 2000; Zadoks 2008). Apart from these introductions, for which the source is known, there are cases of emerging diseases with unclear origin of the pathogen, such as in the tobacco blue mould, Pe tabacina (Lucas 1980); balsamine downy mildew, Pl. destructor (Görg et al. 2017); and basil downy mildew, Pe. 
Fig. 1 Symptoms and morphology of Peronospora belbahrii on lavender. a Infected plants with faint chlorotic lesions and sporulation on the lower leaf surfaces. b Close-up of sporulating lesions. c Sporangiophore. d Terminal branches and ultimate branchlets. e Conidia, the arrow pointing to the secession scar at the former attachment site of an ultimate branchlet to the conidium. Scale bars equal $100 \mu \mathrm{m}$ in $\mathbf{c}$ and $50 \mu \mathrm{m}$ in $\mathbf{d}$ and $\mathbf{e}$



belbahrii (Thines et al. 2009). For these species, it seems possible that they have originated by a host jump to the cultivated crop, similar to the situation of Peronoscleropsora maydis, which became a maize pathogen in Southeast Asia (Suharjo et al., 2020) and Australia (Telle et al. 2011, Shivas et al. 2012) after a host jump from locally occurring Sorghum species. These host jumps are facilitated if the introduced crop is naïve to downy mildew infection because no pathogen causing the disease was present in its original distribution range (Thines 2019).

In the case of basil downy mildew, the pathogen was possibly contracted by basil in Africa (Hansford 1933, 1938), from where it has rapidly spread, most likely due to infested seed lots (Belbahri et al. 2005; Falach-Block et al. 2019; Thines et al. 2009). Peronospora belbahrii is astonishingly diverse for a newly occurring pathogen, suggesting either high mutation rates or multiple introductions. As the pathogen has become a threat to basil production only recently, despite the crop being cultivated for decades before, the latter scenario seems unlikely. Should the high degree of diversification be the result of increased mutation rates, it would enable $P e$.

Fig. 2 Minimum evolution phylogenetic reconstruction based on cox2 (a) and ITS (b) sequences. Numbers on branches indicate bootstrap support in minimum evolution and maximum likelihood analyses as well as Bayesian posterior probabilities, in the respective order. Support values are only given, if at least two independent phylogenetic tools provided support. Values below $60 \%$ bootstrap support or 0.85 posterior probability are not displayed. A minus sign indicates support below the reporting threshold for the presented or an alternate topology 


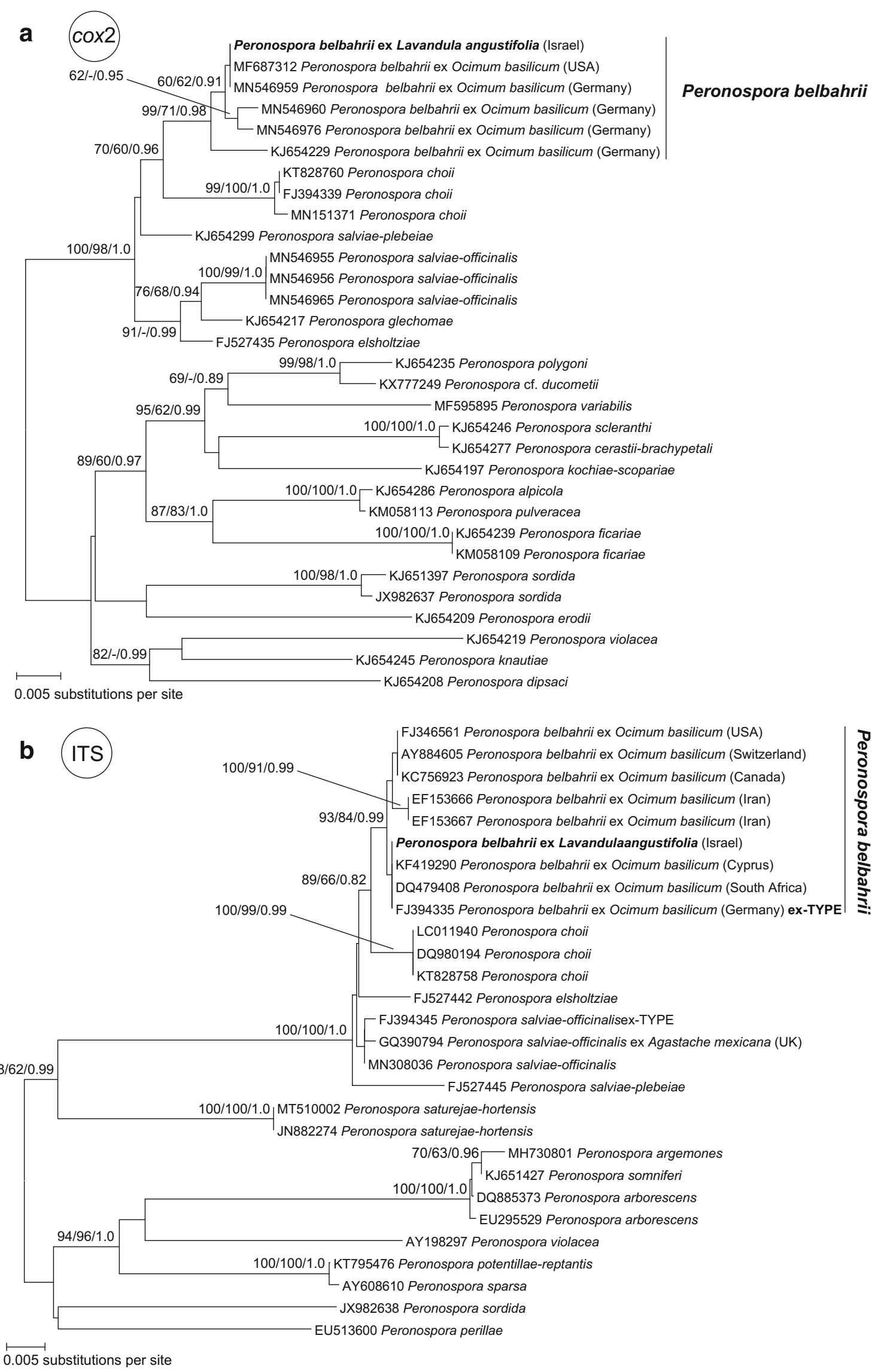


belbahrii to radiate to new hosts in his new distribution range, especially in a setting with frequent contacts and large population sizes of potential new hosts that are related to its current host (Thines 2019). Even though infection trials in a laboratory setting are exaggerating the susceptibility of hosts because of optimised infection parameters and high inoculum load, the results of Ben Naim et al. (2019) seem to support the potential risk of the spread of Pe. belbahrii to other members of the Nepetoideae.

The confirmation in this study of Pe. belbahrii infection in lavender under field conditions suggests that the aggressiveness observed in the laboratory setting might also be present in the field, which might result in jumps to new widely cultivated hosts. Thus, it seems advisable to closely monitor the pathogen in related crops and wild species and to counter infections in basil fields with appropriate phytosanitary measures.

Acknowledgements The first author gratefully acknowledges Christian Printzen, herbarium FR, section for cryptogams, for his continued help in accommodating unusual specimens in the Herbarium Senckenbergianum.

Authors' contributions MT and YC conceived the study; YC and YBN provided material; YBN produced Fig. 1a, b, and MT produced all other figures; ATB and SP processed the samples; MT performed the morphometric analysis, did the phylogenetic reconstructions, and analysed the data; MT wrote the manuscript with contributions from the other authors.

Funding Open Access funding enabled and organized by Projekt DEAL. MT is supported by LOEWE in the framework of the Centre for Translational Biodiversity Genomics. YC is supported by The Plant Council of Israel.

Data availability Sequence data have been deposited in GenBank.

\section{Compliance with ethical standards}

\section{Ethics approval and consent to participate Not applicable.}

\section{Consent for publication Not applicable.}

Competing interests The authors declare that they have no competing interests.

Open Access This article is licensed under a Creative Commons Attribution 4.0 International License, which permits use, sharing, adaptation, distribution and reproduction in any medium or format, as long as you give appropriate credit to the original author(s) and the source, provide a link to the Creative Commons licence, and indicate if changes were made. The images or other third party material in this article are included in the article's Creative Commons licence, unless indicated otherwise in a credit line to the material. If material is not included in the article's Creative Commons licence and your intended use is not permitted by statutory regulation or exceeds the permitted use, you will need to obtain permission directly from the copyright holder. To view a copy of this licence, visit http://creativecommons.org/licenses/by/4.0/.

\section{References}

Altschul SF, Gish W, Miller W, Myers EW, Lipman DJ (1990) Basic local alignment search tool. J Mol Biol 215:403-410

Beakes GW, Thines M (2017) Hyphochytriomycota and Oomycota. In: Archibald J, Simpson A, Slamovits C (eds) Handbook of the Protists. Springer International Publishing, Cham, pp 435-505

Belbahri L, Calmin G, Pawlowski J, Lefort F (2005) Phylogenetic analysis and real time PCR detection of a presumably undescribed Peronospora species on sweet basil and sage. Mycol Res 109: 1276-1128

Ben Naim Y, Falach-Block L, Ben-Daniel BH, Cohen Y (2019) Host range of Peronospora belbahrii, causal agent of basil downy mildew, in Israel. Eur J Plant Pathol 155:789-799

Brilli M, Asquini E, Moser M, Bianchedi PL, Perazzolli M, Si-Ammour A (2018) A multi-omics study of the grapevine-downy mildew (Plasmopara viticola) pathosystem unveils a complex protein coding-and noncoding-based arms race during infection. Sci Rep $8: 1-12$

Choi Y-J, Thines M (2015) Host jumps and radiation, not co-divergence drives diversification of obligate pathogens. A case study in downy mildews and Asteraceae. PLoS One 10:e133655

Choi Y-J, Klosterman SJ, Kummer V, Voglmayr H, Shin HD, Thines M (2015a) Multi-locus tree and species tree approaches toward resolving a complex clade of downy mildews (Straminipila, Oomycota), including pathogens of beet and spinach. Mol Phylogenet Evol 86: 24-34

Choi Y-J, Beakes G, Glockling S, Kruse J, Nam B, Nigrelli L, Ploch S, Shin H-D, Shivas G, Telle S, Voglmayr H, Thines M (2015b) Towards a universal barcode of oomycetes - a comparison of the cox 1 and cox2 loci. Mol Ecol Resour 15:1275-1288

Cohen Y, Van den Langenberg KM, Wehner TC, Ojiambo PS, Hausbeck M, Quesada-Ocampo LM, Lebeda A, Sierotzki H, Gisi U (2015) Resurgence of Pseudoperonospora cubensis: the causal agent of cucurbit downy mildew. Phytopathol 105:998-1012

Constantinescu O (1991) An annotated list of Peronospora names. Thunbergia 15:1-110

de Bary A (1876) Researches into the nature of the potato fungus Phytophthora infestans. J Royal Agr Soc England 12:239-269

Derevnina L, Chin-Wo-Reyes S, Martin F, Wood K, Froenicke L, Spring $\mathrm{O}$, Michelmore R (2015) Genome sequence and architecture of the tobacco downy mildew pathogen Peronospora tabacina. Mol PlMicrobe Interact 28:1198-1215

Edgar RC (2004) MUSCLE: multiple sequence alignment with high accuracy and high throughput. Nucleic Acids Res 32:1792-1797

Falach-Block L, Ben-Naim Y, Cohen Y (2019) Investigation of seed transmission in Peronospora belbahrii the causal agent of basil downy mildew. Agronomy 4:205-216

Fontaine MC, Austerlitz F, Giraud T, Labbé F, Papura D, RichardCervera S, Delmotte F (2013) Genetic signature of a range expansion and leap-frog event after the recent invasion of Europe by the grapevine downy mildew pathogen Plasmopara viticola. Mol Ecol 22:2771-2786

García-Blázquez G, Göker M, Voglmayr H, Martín MP, Tellería MT, Oberwinkler F (2008) Phylogeny of Peronospora, parasitic on Fabaceae, based on ITS sequences. Mycol Res 112:502-512

Gäumann EA (1923) Beiträge zu einer Monographie der Gattung Peronospora Corda. Beiträge zur Kryptogamenflora der Schweiz $5: 1-360$ 
Göker M, Riethmüller A, Voglmayr H, Weiss M, Oberwinkler F (2004) Phylogeny of Hyaloperonospora based on nuclear ribosomal internal transcribed spacer sequences. Mycol Prog 3:83-94

Görg M, Ploch S, Kruse J, Kummer V, Runge F, Choi Y-J, Thines M (2017) Revision of Plasmopara (Oomycota, Peronosporales) parasitic to Impatiens. Mycol Prog 16:791-799

Gráda CÓ (2000) Black'47 and beyond: the great Irish famine in history, economy, and memory. Princeton University Press, Princeton

Gustavsson A (1959) Studies on nordic peronosporas. I. Taxonomic revision. Opera Bot 3:1-271

Hansford CG (1933) Annual report of the mycologist. Rev Appl Mycol $12: 421-422$

Hansford CG (1938) Annual report of the mycologist. Rev Appl Mycol 17:345-346

Hoffmeister M, Ashrafi S, Thines M, Maier W (2020) Two new species of the Peronospora belbahrii species complex, Pe. choii sp. nov. and $P$ e. salviae-pratensis sp. nov., and a new host for Pe. salviaeofficinalis. FUSE 6:39-59

Klein J, Neilen M, van Verk M, Dutilh BE, Van den Ackerveken G (2020) Genome reconstruction of the non-culturable spinach downy mildew Peronospora effusa by metagenome filtering. PLoS One 15: $\mathrm{e} 0225808$

Lucas GB (1980) The war against blue mold. Science 210:147-153

Mishra B, Gupta DK, Pfenninger M, Hickler T, Langer E, Nam B, Paule J, Sharma R, Ulaszewski B, Warmbier J, Burczyk J, Thines M (2018) A reference genome of the European beech (Fagus sylvatica L.). GigaScience 7:giy063

Novotel'nova NS (1962) Plasmopara halstedii as a composite species (The basis for the taxonomic division of the genus Plasmopara on Compositae). Bot Zhurn (Moskva \& Leningrad) 47:970-981 (in Russian with an English summary)

Novotel'nova NS (1966) Downy mildew of sunflower. Taxonomy and biology of the causal agent, pathogenesis of the disease. Nauka, Moskva \& Leningrad (in Russian)

Price MN, Dehal PS, Arkin AP (2010) FastTree2 - approximately maximum-likelihood trees for large alignments. PLoS One 5:e9490

Ronquist F, Teslenko M, van der Mark P, Ayres DL, Darling A, Hohna S, Larget B, Liu L, Suchard MA, Huelsenbeck JP (2012) MrBayes 3.2: efficient Bayesian phylogenetic inference and model choice across a large model space. Syst Biol 61:539-542

Runge F, Thines M (2009) A potential perennial host for Pseudoperonospora cubensis in temperate regions. Eur J Plant Pathol 123:483-486

Runge F, Thines M (2012) Re-evaluation of host specificity of the closely related species Pseudoperonospora humuli and P. cubensis. Plant Dis 96:55-61

Runge F, Ndambi B, Thines M (2012) Which morphological characteristics are most influenced by the host matrix in downy mildews? A case study in Pseudoperonospora cubensis. PLoS One 7:e44863

Sharma R, Xia X, Cano LM, Evangelisti E, Kemen E, Judelson H, Oome S, Sambles C, Van den Hoogen DJ, Kitner M, Klein J, Meijer HJG, Spring O, Win J, Zipper R, Bode HB, Govers F, Kamoun S, Schornack S, Studholme DJ, Van den Ackerveken G, Thines M (2015) Genome analyses of the sunflower pathogen Plasmopara halstedii provide insights into effector evolution in downy mildews and Phytophthora. BMC Genomics 16:741

Shivas RG, Ryley MJ, Telle S, Liberato JR, Thines M (2012) Peronosclerospora australiensis sp. nov. and Peronosclerospora sargae sp. nov., two newly recognized downy mildews in northern Australia, and their biosecurity implications. Aust Plant Pathol 41: $125-130$
Stamatakis A (2014) RAxML version 8: a tool for phylogenetic analysis and post-analysis of large phylogenies. Bioinformatics 30:13121313

Suharjo SIG, Prasetyo J, Fitriana Y, Danaatmadja Y, Budiawan A, Roberts S, Noorhajati N, Amad M, Thines M (2020) Peronosclerospora australiensis is a synonym of $P$. maydis, which is the widespread on Sumatra and distinct from the most prevalent Java maize downy mildew pathogen. Mycol Prog in press

Telle S, Shivas RG, Ryley MJ, Thines M (2011) Molecular phylogenetic analysis of Peronosclerospora (Oomycetes) reveals cryptic species and genetically distinct species parasitic to maize. Eur J Plant Pathol 130:521-528

Thines M (2019) An evolutionary framework for host shifts-jumping ships for survival. New Phytol 224:605-617

Thines M, Choi Y-J (2016) Evolution, diversity, and taxonomy of the Peronosporaceae, with focus on the genus Peronospora. Phytopathology 106:6-18

Thines M, Telle S, Ploch S, Runge F (2009) Identity of the downy mildew pathogens of basil, coleus, and sage with implications for quarantine measures. Mycol Res 113:532-540

Thines M, Denton GJ, Beal EJ, Kilty A, Denton JO, Shin H-D, Choi Y-J (2019) Peronospora aquilegiicola sp. nov., the downy mildew affecting columbines in the UK is an invasive species from East Asia. Europ J Pl Pathol 155:515-525

Thines M, Buaya A, Ali T, Brand T (2020a) Peronospora aquilegiicola made its way to Germany: the start of a new pandemic? Mycol Prog 19:791-798

Thines M, Sharma R, Rodenburg SY, Gogleva A, Judelson HS, Xia X, van den Hoogen J, Kitner M, Klein J, Neilen M, de Ridder D, Seidl MF, van den Ackerveken G, Govers F, Schornack S, Studholme DJ (2020b) The genome of Peronospora belbahrii reveals high heterozygosity, a low number of canonical effectors, and TC-rich promoters. Mol Pl-Microbe Interact MPMI-07-19-0211-R

Trojanová Z, Sedláŕová M, Gulya TJ, Lebeda A (2017) Methodology of virulence screening and race characterization of Plasmopara halstedii, and resistance evaluation in sunflower-a review. Pl Pathol 66:171-185

Viennot-Bourgin G (1949) Les Champignons Parasites des Plantes Cultivées. Masson, Paris

Voglmayr H (2003) Phylogenetic relationships of Peronospora and related genera based on nuclear ribosomal ITS sequences. Mycol Res 107:1132-1142

Voglmayr H, Montes-Borrego M, Landa BB (2014) Disentangling Peronospora on Papaver: phylogenetics, taxonomy, nomenclature and host range of downy mildew of opium poppy (Papaver somniferum) and related species. PLoS One 9:e96838

Yin L, An Y, Qu J, Li X, Zhang Y, Dry I, Wu H, Lu J (2017) Genome sequence of Plasmopara viticola and insight into the pathogenic mechanism. Sci Rep 7:p46553

Yoshida K, Schuenemann VJ, Cano LM, Pais M, Mishra B, Sharma R, Lanz C, Martin FN, Kamoun S, Krause J, Thines M, Weigel D, Burbano HA (2013) The rise and fall of the Phytophthora infestans lineage that triggered the Irish potato famine. eLife 2:e00731

Zadoks JC (2008) The potato murrain on the European continent and the revolutions of 1848. Potato Res 51:5-45

Publisher's note Springer Nature remains neutral with regard to jurisdictional claims in published maps and institutional affiliations. 